\title{
Emergence cerebral oxygen desaturation without hemodynamic compromise in pediatric patients
}

\author{
Younsuk Lee ${ }^{1}$, Junyong In $^{1}$, Seunghyun Chung ${ }^{1}$, Kyoung Ok Kim , Jeoung Hyuk Lee ${ }^{2}$, and Ki-Hyug Kwon ${ }^{1}$ \\ Department of Anesthesiology and Pain Medicine, ${ }^{1}$ Ilsan Hospital, Dongguk University Medical Center, Goyang, ${ }^{2}$ The Catholic \\ University of Korea, Uijeongbu St. Mary's Hospital, Uijeongbu, Korea
}

Background: The regional cerebral oxygen saturation $\left(\mathrm{rSO}_{2}\right)$ decreases significantly during ordinary anesthetic recovery in pediatric patients anesthetized with sevoflurane or desflurane. The present study examined the relationship between $\mathrm{rSO}_{2}$ and the clinical parameters associated with the degree of anesthetic recovery.

Methods: Twelve pediatric patients with American Society of Anesthesiologists physical status 1 were assigned randomly to receive anesthesia with sevoflurane or desflurane. All children underwent general anesthesia for minor surgery. After surgery, the $\mathrm{rSO}_{2}$, the age-adjusted MAC fraction of anesthetic concentration $\left(\mathrm{F}_{\mathrm{E}}\right)$, and the bispectral index (BIS) were recorded over a 10-minute period. The correlations between $\mathrm{rSO}_{2}$ and candidate predictors, such as $\mathrm{F}_{\mathrm{E}}$, BIS, anesthetic, and duration of anesthesia, were analyzed.

Results: All children recovered uneventfully. The lowest observed $\mathrm{rSO}_{2}$ reached $63 \%$ and the maximum decrease in $\mathrm{rSO}_{2}$ was $24 \%$. The mean blood pressure and heart rate were maintained within clinical ranges. The decrease in $\mathrm{rSO}_{2}$ correlated positively with the $\mathrm{F}_{\mathrm{E}}(\mathrm{r}=0.25, \mathrm{P}=0.00)$ and the duration of anesthesia $(\mathrm{r}=0.24, \mathrm{P}=0.01)$, and inversely with the use of sevoflurane $(\mathrm{r}=-0.30, \mathrm{P}=0.00)$.

Conclusions: Despite normal parameters, cerebral desaturation occurred during the emergence of ordinary general anesthesia even without hemodynamic compromise or arterial desaturation. Cerebral desaturation might be associated with the degree of anesthetic recovery and the use of sevoflurane. (Korean J Anesthesiol 2010; 59: 9-12)

Key Words: Anesthesia, Cerebral oximetry, Emergence, Pediatrics.

Received: January 21, 2010. Revised: 1st, February 6, 2010; 2nd, April 1, 2010. Accepted: April 20, 2010.

Corresponding author: Younsuk Lee, M.D., Ph.D., Department of Anesthesiology and Pain Medicine, Ilsan Hospital, Dongguk University Medical Center, Siksa-dong, Ilsandong-gu, Goyang 410-773, Korea. Tel: 82-31-961-7872, Fax: 82-31-961-7864, E-mail: ylee@dongguk.ac.kr (c) This is an open-access article distributed under the terms of the Creative Commons Attribution Non-Commercial License (http:// creativecommons.org/licenses/by-nc/3.0/), which permits unrestricted non-commercial use, distribution, and reproduction in any medium, provided the original work is properly cited. 


\section{Introduction}

The present study was initiated by an incidental finding. The authors observed a significant decrease in the regional cerebral oxygen saturation $\left(\mathrm{rSO}_{2}\right)$, while attempting to recover a pediatric patient who had undergone herniorrhaphy under sevoflurane-based general anesthesia. The patient had been enrolled in another clinical study requiring cerebral oximetry. The same phenomenon was observed repeatedly in consecutive pediatric cases enrolled in the same research. The authors could not find any reports on this phenomenon. It was speculated that the cerebral activation during emergence exceeded the compensatory increase in cerebral blood flow, and that rapid brain recovery could upset the cerebral oxygen supply/demand balance.

This observational study was designed to evaluate the decrease in $\mathrm{rSO}_{2}$ during emergence from ordinary general anesthesia in pediatric patients, and to examine the correlation between the decreases in $\mathrm{rSO}_{2}$ and the degree of anesthetic recovery estimated using anesthetic concentrations.

\section{Materials and Methods}

After obtaining approval of the institutional review board, 12 pediatric patients who underwent minor surgery under general anesthesia were enrolled in this study (Table 1). No premedicant was administered. In addition to standard monitoring equipment, the regional cerebral oxygen saturation, the bispectral index (BIS), and the expired concentration of anesthetic ( $\mathrm{P}_{\mathrm{E}}$ of sevoflurane or desflurane) were monitored. Anesthesia was induced by thiopental ( $5 \mathrm{mg} / \mathrm{kg}$ ) and rocuronium $(0.9 \mathrm{mg} / \mathrm{kg})$, and the trachea was intubated. Muscle

Table 1. Basic Measurements

\begin{tabular}{lcc}
\hline & Desflurane $(\mathrm{n}=6)$ & Sevoflurane $(\mathrm{n}=6)$ \\
\hline Age & $6.5(3.8,9.3)$ & $6.5(4.0,10.5)$ \\
Gender (F/M) & $2 / 4$ & $2 / 4$ \\
Height $(\mathrm{cm})$ & $119.0(104.8,140.8)$ & $127.0(107.5,146.5)$ \\
Weight $(\mathrm{kg})$ & $21(16.8,44.8)$ & $31(20.5,46.8)$ \\
BSA $\left(\mathrm{m}^{2}\right)$ & $0.84(0.69,1.30)$ & $1.06(0.77,1.38)$ \\
Baseline MBP (mmHg) & $79.5(72.0,84.0)$ & $86.5(81.3,89.5)$ \\
Baseline HR (beat/min) & $97.0(80.0,133.0)$ & $114.0(81.3,131.0)$ \\
Baseline BT ( $\left.{ }^{\circ} \mathrm{C}\right)$ & $36.7(36.1,37.1)$ & $36.0(35.1,36.2)$ \\
Baseline ETCO $(\mathrm{mmHg})$ & $32(30,34)$ & $32(30,34)$ \\
rSO $_{2}(\%)$ at time 0 & $85.5(80.5,89.8)$ & $84.5(79.8,87.8)$ \\
Anesthetic duration $(\mathrm{min})$ & $48.0(43.8,65.0)$ & $52.5(46.3,58.8)$ \\
\hline
\end{tabular}

Values are reported as the median (first quartile, third quartile) except gender distribution. No significant difference between the groups $(\mathrm{P} \geq 0.05)$. BSA: body surface area, MBP: mean blood pressure, HR: heart rate, $\mathrm{BT}$ : body temperature, $\mathrm{ETCO}_{2}$ : end-tidal partial pressure of carbon dioxide, $\mathrm{rSO}_{2}$ : regional cerebral oxygen saturation. relaxation was achieved with repeated doses of rocuronium. No opioids were administered. The $\mathrm{FiO}_{2}$ was reduced to 0.4 mixed with medical air, and the fresh gas flow rate was reduced to $2 \mathrm{~L} / \mathrm{min}$. A pediatric sensor (Somasensor ${ }^{\circledR}$; Somanetics, Troy, MI, USA) connected to an INVOS 3100 cerebral oximeter (Somanetics) was attached to the right forehead, and a BIS ${ }^{\mathrm{TM}}$ sensor was attached to the opposite side of each patient in conjunction with a BIS XP monitor (BIS ${ }^{\mathrm{TM}}$ Monitor, Model A-2000 ${ }^{\mathrm{TM}}$, Aspect Medical Systems Inc, Newton, MA, USA). During surgery, the anesthetic concentrations were adjusted by experienced anesthesiologists who were unaware of the purpose of this study. The intraoperative BIS was targeted to 40-50.

When the surgical procedure was completed (time 0 ), anesthetic administration was stopped, the $\mathrm{FiO}_{2}$ and fresh gas flow rate were increased to 1.0 and $6 \mathrm{~L} / \mathrm{min}$, respectively. The respiratory rates and the tidal volume were maintained as during the anesthesia. The $\mathrm{rSO}_{2}, \mathrm{BIS}, \mathrm{P}_{\mathrm{E}}$, body temperature (BT), mean blood pressure (MBP), heart rate (HR), and the end-tidal partial pressure of carbon dioxide $\left(\mathrm{ETCO}_{2}\right)$ were recorded at 0.0 , 0.5, 1.0, 1.5, 2.0, 2.5, 3.0, 3.5, 4.0, 5.0, 8.0, and 10.0 minutes from time $0 . \mathrm{P}_{\mathrm{E}}$ was converted to the age-adjusted MAC-fraction, $\mathrm{F}_{\mathrm{E}}[1]$. Measurements of the MBP were skipped at 0.5, 1.5, 2.5, and 3.5 minutes due to the inevitable latency of noninvasive blood pressure monitoring. The $\mathrm{rSO}_{2}$ and BIS were recorded from the screen. The highest BIS value of the three consecutive measurements at each time period was recorded.

All measurements were stopped when the signs of spontaneous awakening were obvious, e.g., purposeful movements, coughing, straining, or eye opening. The patients were then allowed to recover and transferred to a recovery unit in accordance with local institute guidelines. Pulse oximetry was confirmed to be $100 \%$ throughout the measurement period.

The basic measurements and awakening time were compared using the Mann-Whitney U-test, and are presented as the median and ranges (first quartile, third quartile). The gender distributions were compared using a Fisher's exact test. The $\mathrm{rSO}_{2}, \mathrm{MBP}$, and HR were analyzed using grouped repeated measures ANOVA. Where appropriate, Holm-Sidak procedures were used for multiple comparisons. The measurements at a given time were compared with those at time 0 .

Bivariate correlation analyses were carried out for $\mathrm{rSO}_{2}$ and the 4 candidate variables; duration of anesthesia, $\mathrm{F}_{\mathrm{E}}$, use of sevoflurane (coded 1 for sevoflurane and 0 for desflurane), and BIS. The correlations were described with the Pearson productmoment correlation ( $\mathrm{r}$ ) and $\mathrm{P}$ values.

All inferential statistics of $\mathrm{P}<0.05$ were considered significant. All statistical analyses were performed using version 8.0 of S-PLUS Enterprise Developer (TIBCO Software Inc, Palo Alto, CA, USA). 


\section{Results}

The signs of spontaneous awakening were evident at 8.0 (5.0, 8.5; median, first quantile, third quantile) minutes, and were not significantly different between anesthetics $(\mathrm{P}=0.45)$. The MBP in desflurane and sevoflurane group was $70(67,75) \mathrm{mmHg}$ and $73(68,81) \mathrm{mmHg}$, respectively. The HR in the desflurane and sevoflurane group was $86(70,106)$ beat/min and $96(78,106)$ beat/min, respectively. The temporal changes in the MBP were not significant $(\mathrm{P}=0.31)$, and there were no differences between anesthetics $(\mathrm{P}=0.08)$. However, HR significantly decreased with time $(\mathrm{P}=0.00)$, even though the extent of the HR changes were within the clinically acceptable range. HR changes were similar in both anesthetics $(\mathrm{P}=0.85)$. The $\mathrm{BT}$ and $\mathrm{ETCO}_{2}$ were maintained.

$\mathrm{rSO}_{2}$ showed a temporal decrease $(\mathrm{P}=0.00)$ (Fig. 1$)$, with significance from 2 minutes after time 0 . The anesthetic effect on $\mathrm{rSO}_{2}$ changes was not significant $(\mathrm{P}=0.22)$. The lowest observed $\mathrm{rSO}_{2}$ in each patient in the desflurane and sevoflurane groups was $78 \%(69 \%, 84 \%)$ and $68 \%(64 \%, 73 \%)$, respectively. The maximum changes in the $\mathrm{rSO}_{2}$ were $-13 \%(-8 \%,-13 \%)$ and $-14 \%(-1 \%,-22 \%)$ in the desflurane and sevoflurane group, respectively. $\mathrm{rSO}_{2}$ correlated positively with $\mathrm{F}_{\mathrm{E}}(\mathrm{r}=0.25$, $\mathrm{P}=0.00)$ and the duration of anesthesia $(\mathrm{r}=0.24, \mathrm{P}=0.01)$, and inversely with the use of sevoflurane $(\mathrm{r}=-0.30, \mathrm{P}=0.00)$. There was no correlation between $\mathrm{rSO}_{2}$ and $\mathrm{BIS}(\mathrm{r}=-0.13, \mathrm{P}=0.14)$.

\section{Discussion}

The aim of this study was to evaluate the decrease in $\mathrm{rSO}_{2}$ during emergence from ordinary general anesthesia in pediatric patients, and to examine the correlation between

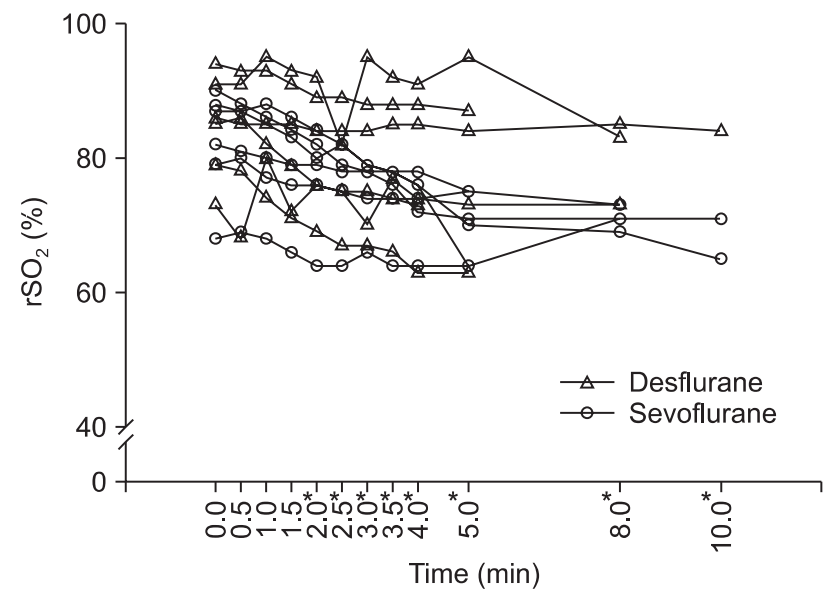

Fig. 1. Temporal changes in the regional cerebral oxygen saturation $\left(\mathrm{rSO}_{2}\right)$. The $\mathrm{rSO}_{2}$ decreases with the time of emergence $(\mathrm{P}=0.00)$. The asterisk $(*)$ denotes a significant difference from time 0 ; both anesthetics show similar results $(\mathrm{P}=0.22)$. the decreases in $\mathrm{rSO}_{2}$ and the degree of anesthetic recovery estimated using anesthetic concentrations. During the ordinary emergence sequence in children, the $\mathrm{rSO}_{2}$ decreased even without an episode of arterial desaturation or overt hemodynamic compromises, and was related to the low anesthetic concentration. Despite values in the normal range, these changes are still significant and correlate with the $\mathrm{F}_{\mathrm{E}}$. The $\mathrm{rSO}_{2}$ is a noninvasive measurement for estimating the level of the cerebral oxygenation in clinical anesthesia, which may be useful for following trends in individual subjects. The inverse correlation between $\mathrm{rSO}_{2}$ and the jugular venous oxygen saturation $[2,3]$ occurs because decreases in the jugular venous oxygen saturation depend on the speed of rewarming after a cardiopulmonary bypass [4].

A shorter anesthesia duration produces lower $\mathrm{rSO}_{2}$, and there is an dynamic discrepancy between the $\mathrm{F}_{\mathrm{E}}$ and $\mathrm{F}_{\mathrm{B}}$ (anesthetic concentration in the brain), which might be intensified by a brief duration of anesthetic uptake in the brain. This classical understanding of volatile anesthetic pharmacokinetics agrees with the present findings that a shorter duration of anesthesia potentiates the decrease in $\mathrm{rSO}_{2}$. Sevoflurane and desflurane require at least $40 \mathrm{~min}$ [5] and $24 \mathrm{~min}$ [6], respectively, to achieve equilibration concentrations between cerebral tissue and blood.

Although we expected no differences between sevoflurane and desflurane, sevoflurane decreased $\mathrm{rSO}_{2}$ further than the same $\mathrm{F}_{\mathrm{E}}$ of desflurane, indicating that they produce different depths of anesthesia. Fassoulaki et al. [7] reported that the $\mathrm{MAC}_{\mathrm{BIS}}$ (MAC to maintain the same BIS) for sevoflurane was greater than that for desflurane, and suggested that the same MAC of sevoflurane produced a higher BIS than desflurane, which explains our findings that sevoflurane produces a lower $\mathrm{rSO}_{2}$.

This is the first report that examined the relationship between cerebral desaturation and the degree of recovery during emergence from ordinary pediatric anesthesia. As the study was observational and preliminary in nature, further controlled trials will be needed to answer many questions, e.g. is the phenomenon observed with intravenous agents? Is it seen in adults? Does the rapid recovery from general anesthesia intensify the decrease of $\mathrm{rSO}_{2}$ ? Does the type of volatile anesthesia have a different effect on the $\mathrm{rSO}_{2}$ ? And is the cerebral desaturation related to the key clinical outcomes, such as emergence delirium/agitation [8], convulsion [9-11], and ischemic events, particularly in children at cerebral risk?

In conclusion, the $\mathrm{rSO}_{2}$ decreases even without an episode of arterial desaturation or overt hemodynamic compromises during ordinary emergence in children. The decrease of $\mathrm{rSO}_{2}$ may correlate inversely with the $\mathrm{F}_{\mathrm{E}}$ and the duration of anesthesia, and positively with the use of sevoflurane. 


\section{References}

1. Lerou JG. Nomogram to estimate age-related MAC. Br J Anaesth 2004; 93: 288-91.

2. Kubo T, Nakagawa I, Hidaka S, Uesugi F, Hamaguchi K, Kato T. Relationship between regional cerebrovascular oxygen saturation and jugular bulb oxygen saturation during carotid endarterectomy. Masui 2005; 54: 1104-8.

3. Nagdyman N, Fleck T, Schubert S, Ewert P, Peters B, Lange PE, et al. Comparison between cerebral tissue oxygenation index measured by near-infrared spectroscopy and venous jugular bulb saturation in children. Intensive Care Med 2005; 31: 846-50.

4. Kawahara F, Kadoi Y, Saito S, Goto F, Fujita N. Slow rewarming improves jugular venous oxygen saturation during rewarming. Acta Anaesthesiol Scand 2003; 47: 419-24.

5. Lu CC, Tsai CS, Ho ST, Chen WY, Wong CS, Wang JJ, et al. Pharmacokinetics of sevoflurane uptake into the brain and body.
Anaesthesia 2003; 58: 951-6.

6. Lu CC, Tsai CS, Ho ST, Chueng CM, Wang JJ, Wong CS, et al. Pharmacokinetics of desflurane uptake into the brain and body. Anaesthesia 2004; 59: 216-21.

7. Fassoulaki A, Kaliontzi H, Petropoulos G, Tsaroucha A. The effect of desflurane and sevoflurane on cerebral oximetry under steadystate conditions. Anesth Analg 2006; 102: 1830-5.

8. Uezono S, Goto T, Terui K, Ichinose F, Ishguro Y, Nakata Y, et al. Emergence agitation after sevoflurane versus propofol in pediatric patients. Anesth Analg 2000; 91: 563-6.

9. Hilty CA, Drummond JC. Seizure-like activity on emergence from sevoflurane anesthesia. Anesthesiology 2000; 93: 1357-9.

10. Terasako K, Ishii S. Postoperative seizure-like activity following sevoflurane anesthesia. Acta Anaesthesiol Scand 1996; 40: 953-4.

11. White PF, Rawal S, Recart A, Thornton L, Litle M, Stool L. Can the bispectral index be used to predict seizure time and awakening after electroconvulsive therapy? Anesth Analg 2003; 96: 1636-9. 